\title{
Aplicação de fertilizantes a taxa variável em agricultura de precisão variando a velocidade de deslocamento ${ }^{1}$
}

\author{
Valmir Werner ${ }^{2}$, José F. Schlosser ${ }^{3}$, Dinorvan Rozin ${ }^{4}$, Eder D. Pinheiro ${ }^{5}$ \& Marçal E. C. Dornelles ${ }^{5}$
}

\begin{abstract}
RESUMO
O desempenho de um conjunto formado por um trator agrícola equipado para agricultura de precisão e um distribuidor centrífugo não adaptado para aplicações de fertilizantes em taxas variáveis, deve ser avaliado, sendo este o objetivo principal do presente estudo. As variações das taxas de aplicação de fertilizantes foram controladas variando-se a velocidade de deslocamento; para tanto, determinou-se largura de trabalho, uniformidade de distribuição transversal e longitudinal e a variação da taxa aplicada de fertilizante NPK. O trabalho foi realizado em uma lavoura comercial de soja, no município de Santa Rosa, RS. Para melhor representatividade dos testes, buscou-se uma condição de solo e relevo da lavoura que melhor representasse uma situação real de uso do conjunto mecanizado. Os resultados mostraram que, na situação de estudo e com o fertilizante aplicado, é possível utilizar o conjunto para larguras de trabalho entre 20,5 e 22,5 m, no circuito de aplicação contínuo e vai-e-vem, com coeficientes de variação (CV) abaixo de $15 \%$. Na análise do perfil longitudinal de distribuição, obtiveram-se valores de CV entre 8,78 e 12,48\%. O conjunto mecanizado permite compor diversas taxas de aplicação variando-se a velocidade de deslocamento no sistema de agricultura de precisão.
\end{abstract}

Palavras-chave: distribuidor centrífugo, taxas de aplicação, distribuição longitudinal

\section{Variable rate fertilizer application in precision farming by varying the travel speed}

\begin{abstract}
The main purpose of this work was to evaluate the performance of a set formed by an agricultural tractor equipped for precision farming and a broadcaster spreader not adapted for applications of fertilizers at variable rates. The variations of the rates of fertilizer application were controlled by varying the travel speed. The width, uniformity of traverse and longitudinal distribution and the variation of the applied rate of NPK fertilizer were determined. The study was accomplished in a commercial farming of soybeans in the city of Santa Rosa, RS. For better reliability of the tests, a soil condition and farming relief that would represent a real situation of use of the mechanized set were looked for. The results showed that, in the study situation and with the used fertilizer, it is possible to use the set for widths between 20.5 and $22.5 \mathrm{~m}$ in the continuous application circuit and back-and-forth, with variation coefficient below $15 \%$. In the analysis of the longitudinal profile of distribution, the values of variation coefficients between 8.78 and $12.48 \%$ were obtained. The mechanized set allows composing several application rates varying the travel speed in the system of precision farming.
\end{abstract}

Key words: broadcaster spreader, application rate, longitudinal distribution

\footnotetext{
Artigo extraído da Dissertação de Mestrado do primeiro autor

2 Doutorando em Engenharia Agrícola, PPGEA/UFSM, CEP 97105-900, Santa Maria, RS. Fone: (55) 3220-8850. E-mail: valmirw@yahoo.com.br

3 DER/UFSM. Fone: (55) 3220-8850. E-mail: schlosse@smail.ufsm.br

${ }^{4}$ Mestre. Fone: (55) 9972-8535. E-mail: rozindinorvan@johndeere.com

${ }^{5}$ Acadêmico do Curso de Agronomia/UFSM. Fone: (55) 8128-3534. E-mail: eder.pinheiro@gmail.com; (55) 9603-0227. E-mail: dornellesagro@yahoo.com.br
} 


\section{INTRODUÇÃO}

Ocorreu, nas últimas décadas, grande evolução na agricultura brasileira conseguindo-se dobrar, praticamente, a produção e a produtividade de algumas das principais culturas sem, no entanto, aumentar o tamanho das áreas de produção na mesma proporção; todavia, existe a necessidade de aumentar a produção de forma sustentável, sobretudo em relação à preservação do meio ambiente. Na busca desses objetivos surgiram, então, as ferramentas de agricultura de precisão, que se inserem, nesse contexto, como ferramenta de gerenciamento, possibilitando que se acompanhem, minuciosamente, as culturas, conhecendo-as e descobrindo detalhes das lavouras a cada ciclo de produção visando não apenas aumentar a produtividade mas, também, manter a quantidade de insumos ou mesmo a produtividade, reduzindo a quantidade de insumos aplicados em determinada área (Blackmore,1994).

O processo de adoção da agricultura de precisão encontra-se na fase em que o agricultor busca solucionar os principais problemas levantados em sua lavoura, através de mapas de produtividade, fertilidade etc. Na solução dos impasses de fertilidade, a aplicação de fertilizantes a taxa variável é, hoje, uma necessidade, razão por que se desenvolvem tecnologias para aplicações em taxa variada atuando-se diretamente sobre as variações espaciais e temporais; para isto, são montados dispositivos em máquinas de aplicação que comandam as decisões de variação da aplicação, processando os dados dos sensores (TDP, velocidade, posição no campo etc) e os dados inseridos pelo usuário aplicando-se, portanto, a dose necessária (Dallmeyer \& Schlosser, 1999).

Delafosse \& Bogliani (1989) enfatizam que, devido à tendência dos aplicadores a lanço de concentrar maior quantidade de produto no centro geométrico da máquina, deve-se efetuar o levantamento do perfil transversal através de ensaios; por meio desse perfil, pode-se determinar a porcentagem adequada de sobreposição que resulta em uma aplicação homogênea. Os autores utilizam, na análise, como parâmetros, o peso médio do produto depositado nos coletores com e sem sobreposição de passadas adjacentes, o coeficiente de variação e a largura efetiva de trabalho.

Segundo Molin et al. (2001), os distribuidores a lanço estão sendo utilizados como máquina alternativa, tanto nas aplicações em cobertura como em aplicações pré-plantio; na maioria dos casos, porém, não se tem informação confiável quanto à qualidade de aplicação de grande parte das máquinas disponíveis no mercado brasileiro.

Em relação à uniformidade de distribuição transversal de produtos, as normas ISO (1981) e ASAE (1995) definem a utilização do coeficiente de variação (CV) para determinação da largura efetiva de trabalho, como medida de desuniformidade da dose aplicada, com a sobreposição de passadas, não estabelecendo, porém, um CV mínimo padrão.

Dallmeyer (1985) recomenda que a análise do perfil transversal seja feita através do CV e a largura de trabalho selecionada como sendo efetiva aquela em que, após a sobreposição, o CV seja de 15\%; da mesma forma, a avaliação da uniformidade de distribuição transversal de fertilizantes uti- lizando distribuidores centrífugos, conforme Glover \& Baird (1973) apud Weiss (1986) é feita pelo coeficiente de variação; eles consideram, como grau de uniformidade de distribuição muito bom, o CV até $10 \%$; bom de 10 a 20\%; regular de 20 a 33\% e deficiente o CV acima de 33\%.

Com este trabalho, teve-se por objetivo principal avaliar, a campo, o desempenho de um conjunto mecanizado formado por um trator agrícola e um distribuidor centrífugo a lanço não adaptado para aplicações de fertilizantes a taxas variáveis; para tanto, determinou-se a largura de trabalho efetiva, a uniformidade de distribuição transversal e a variação da distribuição ao longo do perfil longitudinal de deslocamento do conjunto mecanizado e se trabalhou com a hipótese de que é possível realizar aplicação de fertilizantes a taxas variáveis, em agricultura de precisão, utilizando-se a velocidade de deslocamento para variar as referidas taxas.

\section{MATERIAL E MÉTODOS}

Os trabalhos de campo foram realizados por uma equipe formada de técnicos da AGCO do Brasil e Universidade Federal de Santa Maria, em uma lavoura de soja, na localidade de Senador Salgado Filho, município de Santa Rosa, RS. Para melhor representatividade dos testes, buscou-se uma condição de solo e relevo de lavoura praticamente plana e que se aproximasse o máximo de uma real situação de uso do conjunto mecanizado. O fertilizante utilizado nos testes foi um granulado com formulação 2-16-28; para melhor caracterizar o produto granulado utilizado realizou-se o teste de granulometria, conforme a Portaria 31, Brasil (1982), cujos produtos, constituídos de grânulos, deverão ser 100\% menores que 4 mm de diâmetro (ABNT nº 5), com um máximo de $5 \%$ dos grânulos com diâmetro inferior a $0,5 \mathrm{~mm}$ (ABNT n $\left.{ }^{\circ} 35\right)$.

O conjunto utilizado na realização do trabalho foi um trator da marca Massey Ferguson, modelo MF5320 com TDA (Tração dianteira auxiliar), e um distribuidor centrífugo de sólidos da marca Stara Sfil, modelo Tornado 1300; equipouse o trator com um terminal "Datavision”, sensor de rotação da TDP, receptor GPS e um radar; esses componentes fazem parte do sistema para agricultura de precisão "Fieldstar" da AGCO, o qual permite o monitoramento e controle dos equipamentos utilizados em agricultura de precisão. No trabalho, utilizaram-se essas ferramentas para monitorar as funções do trator, tais como rotação do motor, rotação na TDP, velocidade de operação e posicionamento. O conjunto formado pelo trator, equipado para aplicações em taxas variáveis, e o distribuidor de fertilizantes, não monitorado, foi empregado como alternativa para a realização de aplicações em doses variáveis através da velocidade de deslocamento para variar as taxas de produto a ser aplicado em cada momento.

O trator usado apresenta transmissão tipo sincronizada de doze marchas à frente e é equipado com pneus traseiros 18.4$34 \mathrm{R} 1$, atingindo velocidades entre $1,2 \mathrm{~km} \mathrm{~h}^{-1}$ a $30,1 \mathrm{~km} \mathrm{~h}^{-1}$. Para realização do trabalho a campo selecionaram-se quatro marchas, que foram: $3^{\mathrm{a}}$ (reduzida $2^{\mathrm{a}}$ baixa), $4^{\mathrm{a}}$ (reduzida $2^{\mathrm{a}}$ alta), $5^{\text {a }}$ (reduzida $3^{\text {a }}$ baixa) e $6^{\text {a }}$ (reduzida $3^{\text {a }}$ alta), na rotação 
de trabalho de 1900 rpm, no qual o trator desenvolve 540 rpm na tomada de potência; nesta condição, o trator desenvolve velocidades teóricas de 2,9; 3,5; 5,3 e 6,4 $\mathrm{km} \mathrm{h}^{-1}$ que, de maneira geral, são velocidades que possibilitam, ao operador, manter um perfeito controle sobre o conjunto e, ainda, realizar as respectivas seleções de velocidade nos locais predeterminados pelo mapa de aplicação de fertilizantes; determinouse, também, a velocidade real desenvolvida pelo trator nas diferentes marchas cronometrando-se os tempos para percorrer uma distância de 50 m; enfim, para as avaliações em cada marcha, realizaram-se três repetições.

Fez-se a determinação da vazão estática do equipamento em três diferentes aberturas (3,0; 3,5 e 4,0), com o equipamento abastecido entre 40 e $50 \%$ da capacidade do reservatório, como definido pela ASAE (1995); para tanto, utilizouse um filme plástico, o qual foi disposto ao redor do equipamento para coleta do produto aplicado e, para cada abertura do sistema dosador do equipamento, realizaram-se amostragens de um minuto cada uma, em três repetições.

A determinação da faixa de distribuição transversal e longitudinal foi realizada a campo utilizando-se coletores com dimensões padronizadas de 0,5 x 0,5 m, com profundidade de $0,15 \mathrm{~m}$, enquanto na determinação da distribuição transversal os coletores foram colocados lado a lado, perpendicularmente ao sentido do deslocamento do conjunto tratorizado cobrindo toda a faixa de aplicação do equipamento; por outro lado, para determinação da distribuição longitudinal os coletores foram colocados paralelos ao deslocamento, no lado esquerdo, a $3 \mathrm{~m}$ da linha central de deslocamento do conjunto mecanizado; após cada passagem do conjunto, realizou-se a coleta individualizada de cada coletor para posterior pesagem do material; a partir da obtenção dos dados, realizou-se a análise para verificação das características das faixas de deposição; utilizou-se o CV de 15\%, ou inferior, para determinação da largura de aplicação recomendada, conforme Wolf \& Smith (1979). Realizaram-se sobreposições dos dados utilizando-se os dois sentidos, “vai-e-vem” e “contínuo", descritos por Milan \& Gadanha Júnior (1996). O deslocamento "vai-e-vem” pode ser descrito como sendo aquele em que se trabalha em faixas adjacentes e paralelas; neste sentido de trabalho, sempre se sobrepõe o produto lançado para a direita com o produto lançado para a direita na faixa anterior; já no sentido contínuo, o operador trabalha no contorno da área, situação em que se sobrepõe o produto lançado para a direita com o lançado anteriormente à esquerda.

O distribuidor é de acoplamento aos três pontos de engate do trator e apresenta dois discos centrífugos de distribuição de produtos com 4 aletas cada um, sendo duas de tamanho menor, aqui denominadas aletas $\mathrm{P}$, além de duas maiores conhecidas como aletas G, em que cada uma apresenta 4 regulagens de posição sendo a última do sentido de giro, neste trabalho chamada posição 1; as regulagens das posições 2,3 e 4, estão avançadas em relação à posição 1; por outro lado, as variações nas posições das aletas sobre os discos de distribuição têm influência direta no perfil de distribuição transversal dos produtos; quando as aletas são atrasadas, tendem a diminuir a largura de trabalho do distribuidor e avançandoas (posição 3 ou 4) afetam a qualidade de distribuição. Antes de se iniciar este trabalho realizaram-se alguns ensaios de campo verificando qual o melhor posicionamento das aletas sobre os dois discos do distribuidor utilizando-se, para tal, algumas regulagens prévias fornecidas pelo fabricante.

Na determinação do perfil longitudinal colocou-se uma baliza a $10 \mathrm{~m}$ do início da fila de bandejas, servindo de indicação ao operador como se tratando do momento exato para a troca de marchas (velocidade); este momento foi indicado ao operador pelo terminal eletrônico presente na cabine do trator ("Datavision”), seguindo a prescrição do mapa de aplicação a taxas variáveis. Neste trabalho e com base nas avaliações de campo, considerou-se a distância de 7 m anteriores a baliza até $2 \mathrm{~m}$ após, como sendo a distância necessária à variação das dosagens. Realizaram-se três repetições (passagens) ao longo da linha de bandejas para cada troca de marchas.

Aqui, as variáveis foram definidas como sendo a velocidade de deslocamento, a vazão de produto e a largura de trabalho.

\section{RESULTADOS E DISCUSSÃO}

Nas marchas selecionadas obtiveram-se velocidades reais de 3,4; 4,4; 5,6 e 7,4 $\mathrm{km} \mathrm{h}^{-1}$ na rotação de $1900 \mathrm{rpm}$ do motor, a qual proporciona $540 \mathrm{rpm}$ na tomada de potência, enquanto se empregou, para os cálculos das taxas de aplicação, a velocidade real determinada; na teoria, pode-se trabalhar nas aplicações de fertilizantes com velocidades maiores, o que dependerá principalmente da habilidade do operador em manter um perfeito controle sobre a máquina, realizando as seleções de velocidade nos momentos predefinidos pelo mapa de aplicação, nas diferentes situações de campo.

Apresentam-se, na Tabela 1, os valores das vazões médias obtidas em três repetições, nas aberturas 3,0, 3,5 e 4,0 do sistema dosador do distribuidor centrífugo utilizado.

Tabela 1. Vazões médias nas aberturas 3,0, 3,5 e 4,0 da escala do sistema dosador

\begin{tabular}{ccc}
\hline Abertura dosador & $\begin{array}{c}\text { Rotação do motor } \\
(\mathbf{r p m})\end{array}$ & $\begin{array}{c}\text { Vazão média } \\
\left(\mathbf{k g ~ m i n}^{-1}\right)\end{array}$ \\
3,0 & 1900 & 29,04 \\
3,5 & 1900 & 47,58 \\
4,0 & 1900 & 58,62 \\
\hline
\end{tabular}

O teste de granulometria do produto utilizado neste trabalho, apresentou os seguintes resultados: 1,0\% de grânulos maiores que $4 \mathrm{~mm}$; 94,5\% entre 2 e $4 \mathrm{~mm} ; 4,0 \%$ entre 0,5 e $2 \mathrm{~mm}$ e $0,5 \%$ menor que $0,5 \mathrm{~mm}$; portanto, $98,5 \%$ dos grânulos estão entre 0,5 e $4 \mathrm{~mm}, 0,5 \%$ se acha na faixa de tolerância e apenas $1,0 \%$ não se enquadrou nos padrões definidos pela Portaria 31, Brasil (1982).

Para determinação da largura efetiva de trabalho coletaram-se amostras de campo nas diferentes velocidades. $\mathrm{Na}$ Figura 1 se visualizam os coeficientes de variação realizando-se as sobreposições em diferentes larguras de trabalho e nos sentidos de deslocamento contínuo e "vai-e-vem". 


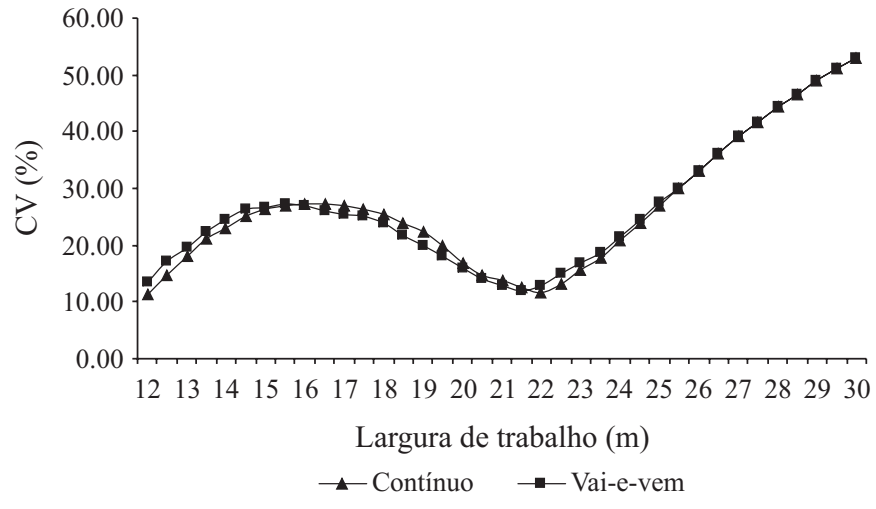

Figura 1. Uniformidade de distribuição nos sistemas de deslocamento contínuo e vai-e-vem, com as aletas grandes na posição 3 (G3) e pequenas na posição $4(\mathrm{P} 4)$, na $3^{\mathrm{a}}$ marcha

Observando-se os coeficientes de variação com as aletas grandes na posição 3 e pequenas na posição 4, pode-se recomendar o equipamento para larguras entre 20,5 e 22,5 m nos dois circuitos de aplicação sem que o CV aumente para valores acima dos 15\%, estabelecidos com base em Dallmeyer (1986); além disso, esta foi a melhor regulagem obtida para a situação do trabalho, fertilizante e equipamentos utilizados, com uma largura efetiva de trabalho de 22,5 m; no circuito de aplicação contínuo, os coeficientes de variação foram um pouco inferiores se comparados ao circuito “vai-e-vem”. Milan \& Gadanha Júnior (1996) afirmam que, via de regra, o circuito contínuo apresenta tendência para corrigir as imperfeições enquanto o circuito "vai-e-vem" as amplifica, explicado pelo fato de que no sistema "vai-e-vem" a sobreposição das passadas se dá do mesmo lado e no sistema contínuo ocorre sobreposição de lados diferentes. É importante que se faça, aqui, a observação de que o menor coeficiente de variação encontrado no circuito contínuo foi de $11,7 \%$ na largura de $22 \mathrm{~m}$ e $12,0 \%$ na largura de 21,5 m no circuito de "vai-e-vem”, o que permite salientar que se deve ter em mente que as taxas de fertilizantes realmente aplicadas não condizem, muitas vezes, com aquelas para as quais se aferem os equipamentos, existindo sempre alguma variação; por outro lado, as aplicações a taxas variáveis tendem a corrigir, de maneira mais precisa, a variabilidade espacial que o sistema convencional, o qual é embasado apenas em aplicações médias.

Ressalta-se, portanto, a importância em se trabalhar a agricultura de precisão realizando-se aplicações através das chamadas "zonas de manejo", que englobam áreas maiores com características similares, haja vista que grande parte dos equipamentos de distribuição de fertilizantes trabalha com oscilação nas taxas de aplicação e na uniformidade de distribuição, maior que as taxas apresentadas em alguns mapas de aplicação.

Os perfis de distribuição transversal de fertilizantes nos circuitos de aplicação em contorno e em vai-e-vem, podem ser visualizados na Figura 2, nas quais se acham, também, os perfis na largura efetiva de trabalho de 22,5 m que, por sinal, apresentou os menores coeficientes de variação na máxima largura de trabalho, nos dois sentidos de operação.

A distribuição longitudinal de fertilizantes utilizandose um conjunto trator e distribuidor centrífugo, alterando a velocidade de deslocamento como forma de variar a taxa de aplicação de fertilizantes, está representada pelos perfis longitudinais e as respectivas trocas de velocidade, na Figura 3.

Pode-se identificar, na Figura 3, que a distribuição longitudinal ocorreu na forma de pequenos ciclos que se repetiram em todas as velocidades de trabalho, o que pode ser

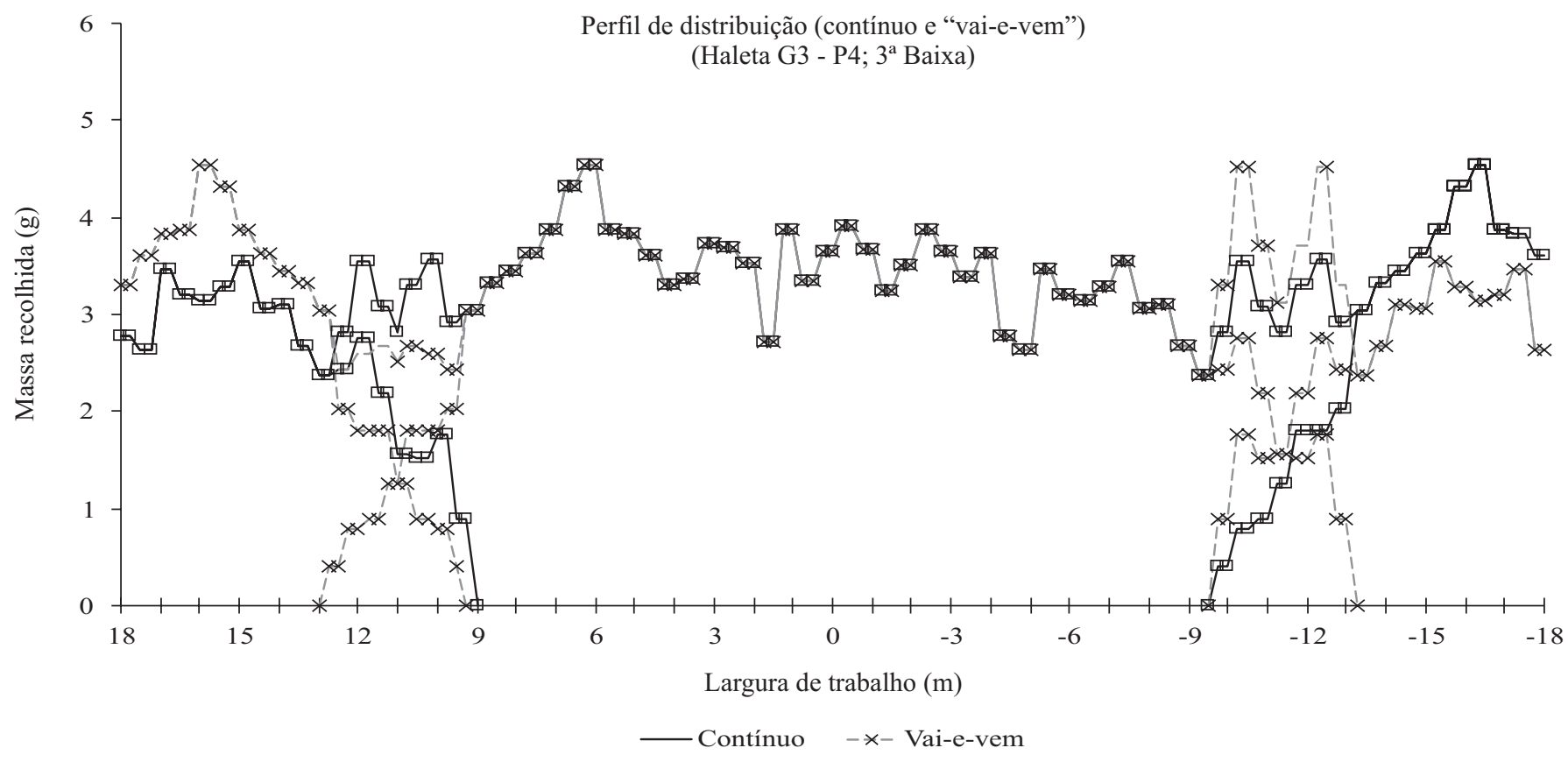

Figura 2. Perfil médio de distribuição transversal utilizando a faixa de aplicação de 22,5 metros no circuito de aplicação contínuo e vai-e-vem com as aletas grandes na posição 3 e pequenas na posição 4 


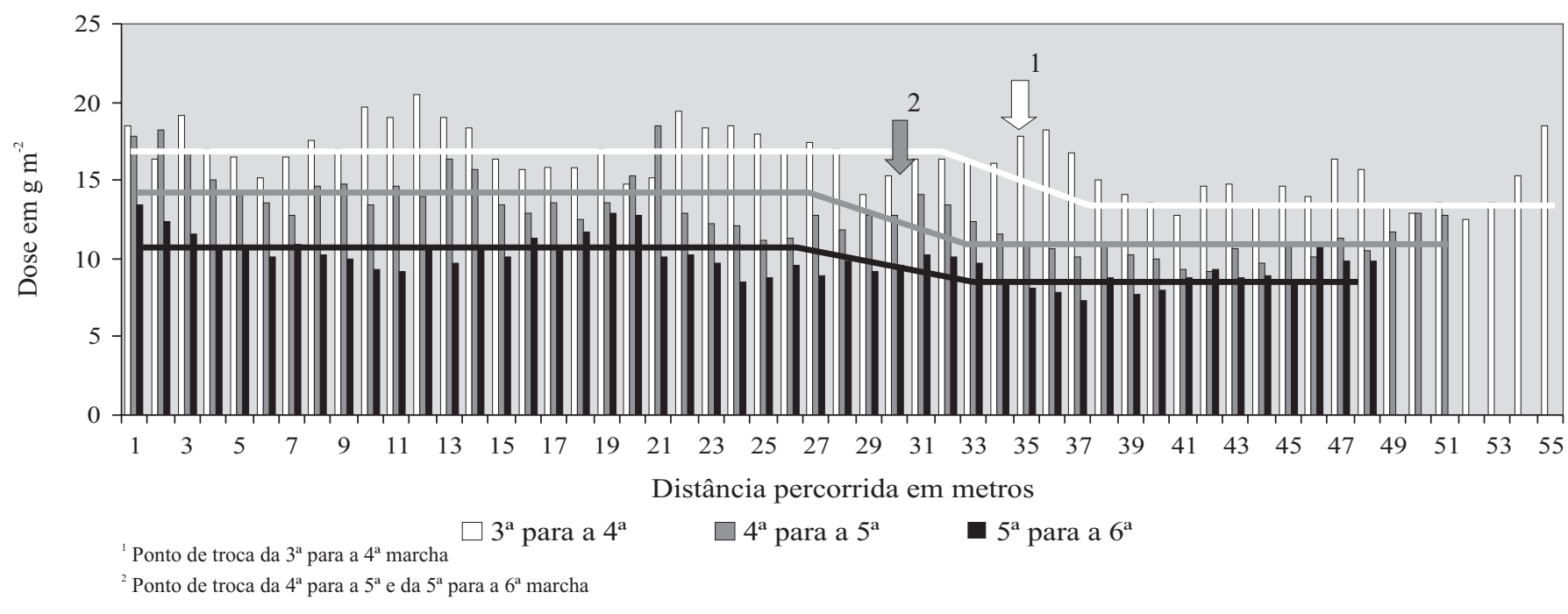

Figura 3. Distribuição longitudinal conforme alterações da $3^{\mathrm{a}}$ para a $4^{\mathrm{a}}, 4^{\mathrm{a}}$ para a $5^{\mathrm{a}}$ e $5^{\mathrm{a}}$ para a $6^{\mathrm{a}}$ marcha

atribuído, sem dúvida, à granulometria do produto utilizado, que interfere na sua fluidez, através do sistema dosador do equipamento. Nos denominados pontos de transição não ocorreram grandes acúmulos de produto, fazendo crer que a troca de velocidades se deu de forma normal. Ao se analisar os dados da Tabela 2, verifica-se que a quantidade de produto aplicado nos pontos de transição apresenta valores intermediários entre as referidas velocidades caracterizando claramente a alteração entre uma taxa e outra.

Também se nota, na Tabela 2, que os coeficientes de variação longitudinais apresentam valores entre 8,78 e $12,48 \%$, que possibilitam a utilização do equipamento para aplicações de fertilizantes a taxas variáveis, variando-se a velocidade de aplicação. É oportuno que aqui se faça uma observação quanto à qualidade de trabalho apresentado pelos distribuidores centrífugos, de maneira geral; além da desuniformidade de distribuição transversal (Figura 2), considera-se a variabilidade na distribuição longitudinal que, na maioria dos trabalhos, se encontra com coeficiente de variação em torno de $10 \%$, porém na situação em que se realizou este trabalho variações de fertilidade em um talhão inferiores a 8,78\% dificilmente podem ser corrigidas utilizando-se o equipamento e o produto, por se tratar da menor variação determinada, o que possibilita inferir que as aplicações a taxas variáveis utilizando-se as denominadas zonas de manejo, serão mais apropriadas visto que pequenas variabilidades de fertilidade dificilmente serão corrigidas usando-se este tipo de distribuidores.

Tabela 2. Vazão de produto nas marchas e nas áreas de transição

\begin{tabular}{|c|c|c|c|c|}
\hline Marcha & $\begin{array}{l}\text { Média } \\
\left(\mathrm{g} \mathrm{m}^{-2}\right)\end{array}$ & $\begin{array}{l}\text { Dosagem } \\
\left(\mathrm{kg} \mathrm{ha}^{-1}\right)\end{array}$ & Desvio padrão & $\begin{array}{l}\text { CV } \\
(\%)\end{array}$ \\
\hline 3 & 17,38 & 173,81 & 1,53 & 8,78 \\
\hline Transição & 16,44 & 164,44 & - & - \\
\hline 4 & 14,20 & 142,02 & 1,50 & 10,56 \\
\hline Transição & 12,46 & 124,61 & - & - \\
\hline 5 & 10,67 & 106,66 & 0,99 & 9,25 \\
\hline Transição & 9,43 & 94,29 & - & - \\
\hline 6 & 9,03 & 90,32 & 1,13 & 12,48 \\
\hline
\end{tabular}

Na Tabela 3 se encontram algumas possíveis taxas de aplicação calculadas neste trabalho, utilizando-se a largura de trabalho, as vazões e as velocidades determinadas, que podem ser utilizadas pelos agricultores para aplicações a taxas variáveis em agricultura de precisão, variando a velocidade de aplicação. Nota-se que é possível compor diversas taxas de aplicação necessitando-se, para isso, determinar a velocidade de deslocamento nas diferentes velocidades, determinar a vazão do sistema dosador do equipamento a ser utilizado, determinar a largura útil de aplicação do equipamento e, com base nos mapas de fertilidade e produção, determinar o tipo de fertilizante e as taxas de aplicação recomendadas.

Tabela 3. Taxas de aplicação (kg ha-1) na largura de trabalho de 22,5 m

\begin{tabular}{crcr}
\hline \multirow{2}{*}{ Marcha $\backslash$ Regulagem } & \multicolumn{3}{c}{ Dosagem (kg ha-1) } \\
\cline { 2 - 4 } & $\mathbf{3 , 0}$ & $\mathbf{3 , 5}$ & $\mathbf{4 , 0}$ \\
$3^{\mathrm{a}}$ & 228,8 & 374,9 & 461,9 \\
$4^{\mathrm{a}}$ & 174,9 & 286,5 & 353,0 \\
$5^{\mathrm{a}}$ & 138,8 & 227,4 & 280,1 \\
$6^{\mathrm{a}}$ & 104,4 & 171,1 & 210,8 \\
\hline
\end{tabular}

\section{CONCLUSÕES}

1. A variação da velocidade pode ser utilizada para alterar as taxas de aplicação de fertilizantes a lanço.

2. Variando-se a velocidade de deslocamento, largura de trabalho e se utilizando a abertura 4 do sistema dosador, pode-se obter quatro taxas de aplicação entre 200 e $470 \mathrm{~kg} \mathrm{ha}^{-1}$, que poderiam representar quatro diferentes zonas de manejo em agricultura de precisão, sendo que o momento de troca de marchas pode ser indicado pelo terminal “Datavision”, localizado na cabine do operador.

3. Na regulagem de aletas grandes na posição 3 e pequenas na posição 4, permite-se utilizar o equipamento para larguras entre 20,5 e 22,5 m nos dois circuitos de aplicação sem que os valores de CV ultrapassem 15\%. 
4. Nas escalas do sistema dosador, largura de trabalho determinada e nas velocidades selecionadas, pode-se variar as taxas de aplicação entre 104 e $461 \mathrm{~kg} \mathrm{ha}^{-1}$ para o fertilizante utilizado.

\section{LITERATURA CITADA}

ASAE - American Society of Agricultural Engineers. ASAE S341.2 (Dec 92). Procedure for measuring distribution uniformity and calibrating granular broadcast spreaders. St Joseph: ASAE Standards, 1995, p.177-179.

Blackmore, S. Precision farming: An overview. Agricultural Engineering, St. Joseph, p.86-88, 1994.

Brasil. Portaria n. 31, de 08 de julho de 1982 (Aprova os métodos analíticos padrões oficiais, para análise de corretivos, fertilizantes e inoculantes sujeitos à inspeção e fiscalização). Diário Oficial da União, Brasília, 09/03/83. Sec. I. p.10763-93. 1982.

Dallmeyer, A. U. Desenvolvimento de um rotor cônico para distribuição centrífuga de calcário seco. Santa Maria: UFSM, 1985. 118p. Dissertação Mestrado

Dallmeyer, A. U. As máquinas utilizadas na distribuição e incorporação de calcário. In: Simpósio sobre a Aplicação de Calcário na Agricultura, Ipanema, 1986, Campinas. Anais... Campinas: Fundação Cargill, 1986, p.23-39.
Dallmeyer, A. U.; Schlosser, J. F. Mecanización para la agricultura de precisión. In: Blu, R. O.; Molina, L. F. (org.). Agricultura de precisión - introducción al manejo sitio-específico, 1999. Chillán: INIA e Cargill Chile, 1999, cap.3, 128p.

Delafosse, R. M.; Bogliani, M. P. Fertilizadoras centrífugas, la importancia de una correcta elección, uso y mantenimiento. Santiago: Oficina Regional de la FAO para América Latina el Caribe, 1989, 32p.

ISO - International Standard Organization. Método de ensayos de distribuidores de abonado “a voleo". 5690/1. In: Maquinaria para siembra y abonado: Métodos de ensayo, Madrid: Focitec, p.95-114. 1981.

Milan, M.; Gadanha Júnior, C. D. Ensaios \& certificação de máquinas para aplicação de fertilizantes e corretivos. In: Mialhe, L. G. (org.). Máquinas agrícolas: Ensaios \& certificação. Piracicaba: Shekinah, 1996, p.515-550.

Molin, J. P.; Menegatti, L. A.; Pereira, L. L.; Creminini, L. C.; Evangelista, M. Avaliação do desempenho de distribuidora de produtos sólidos a lanço em doses variáveis de uréia. In: Congresso Brasileiro de Engenharia Agrícola, 30, 2001, Foz do Iguaçu. Anais... Foz de Iguaçu: SBEA, 2001, CD Rom.

Weiss, A. Desenvolvimento de um distribuidor helicoidal para calcário seco. Santa Maria: UFSM, 1986. 79p. Dissertação Mestrado

Wolf, D. D.; Smith, E. S. Uniformity of seed and fertilizer distribution with a hand-operated spinning spreader. Transactions of the ASAE, St. Joseph, v.22, n.4, p.761-2/70, 1979. 